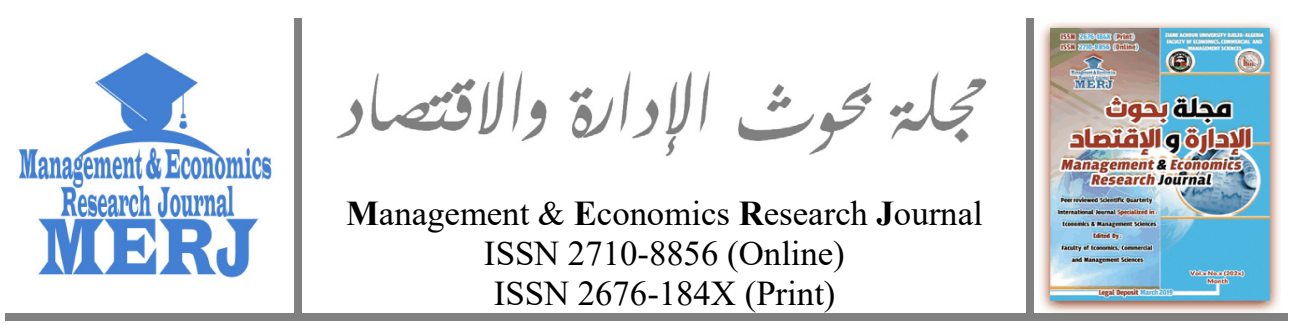

Vol. 4 No. 1 (2022): March, pp. 101-127

https://doi.org/10.48100/merj.2022.189

Check for updates

\title{
Information and Communications Technology and the Level of Income in Africa
}

\author{
Musa Ilias Biala ${ }^{\bullet}\left(\mathbb{D}\right.$, Yusuf Toyin Yusuf ${ }^{2}$ \\ ${ }^{1,2}$ Department of Economics and Development Studies, Kwara State University, Malete \\ (Nigeria) \\ ${ }^{1} \bowtie$ bialamusa@yahoo.com, ${ }^{2} \bowtie$ ytoyinyusuf@gmail.com
}

Published online: 01-03-2022

\section{How to Cite:}

Biala, M. I., \& Yusuf, Y. T. (2022). Information and Communications Technology and the Level of Income in Africa. Management \& Economics Research Journal, 4(1), 101-127. https://doi.org/10.48100/merj.2022.189

\begin{abstract}
:
Information and communications technology has been identified as a factor that drives income, economic growth, and development. Because of this, several studies have been conducted to ascertain ICT's effects on economic growth. However, such studies failed to examine whether real per capita income influences the effect of ICT on income level and whether the effect of ICT on income level differs among regions of African countries. This study, therefore, investigated the effect of ICT on income level. Specifically, it examined whether real per capita income influences the effect of ICT on income level and whether the effect of ICT on income level differs among the sub-regions of African countries. Thus, empirical models were estimated using the panel regression analysis with fixed-effect and randomeffect estimators. The results show that ICT positively affects income level in Africa, and real income per capita influences the effect of ICT on income
\end{abstract}

- Corresponding author: Department of Economics and Development Studies, Kwara State University, Malete (Nigeria).

[₫bialamusa@yahoo.com]

(C)2022 the Author(s). This is an open-access article distributed under the terms of (CC BY-NC 4.0) which permits use, distribution and reproduction in any medium, provided the original work is properly cited and is not used for commercial purposes.

Faculty of Economics, Commercial \& Management
Sciences, Ziane Achour University of Djelfa, BP
3117, Djelfa - Algeria


level. In contrast, the effect of ICT on income level differs among African regions. The effect is larger in Eastern, Southern, and Northern African countries than in other regions. Therefore, authorities should consider investment in ICT as a tool or mechanism for enhancing income.

Keywords: Fixed Telephone Subscription, Mobile Cellular Subscription, Internet Users, Fixed Broadband Subscriptions, ICT.

JEL Codes: O10, O11, O30.

\section{Introduction}

Electronic equipment for storing, analyzing, distributing, or communicating information, known as information and communications technology (ICT), has become vital to economic activities today. The importance of ICT in economic and social development has arisen naturally since its inception in the mid-nineties (Hodrab et al., 2016). Most firms and consumers now use computers and the internet for their economic activities to provide themselves with more diversified and customized products and improved product quality (Farhadi, Ismail \& Fooladi, 2012). ICT reduces the economic impact of physical distances, access to information, and the cost of establishing new small businesses, making businesses more efficient and competitive (Can \& Terziev, 2016).

Consequently, many developing countries now consider ICT one of the key tools driving productivity growth, and it has become an integral part of development strategies. ICT is orchestrating globalization and offers a unique opportunity for developing countries to free themselves from historical and geographic constraints, allowing trade and economic activities to be conducted as efficiently as in the developed world. An evolving and increasingly robust ICT infrastructure has fundamentally changed the nature of global relationships, sources of competitive advantage, and opportunities for economic and social development. Technologies like the internet, personal computers, broadband, and wireless telephony have created an interconnected global network of individuals, firms, and governments (Veeramacheneni et al., 2011).

Meanwhile, human welfare via income enhancement is one of the significant policy agendas of policymakers across developed and developing economies. However, it has been uninspiring and unsatisfactory in most developing African countries. The insufficient income level can be explained partly by inappropriate policies, which can be addressed if policymakers are better informed of the determinants of income level. Theoretical and empirical studies have sought to shed light on factors determining the income level, including ICT, to assist policymakers in this regard. The impact of ICT 
on income level has become a theoretical and empirical issue that has lingered on. The role of ICT activities in enhancing income is at the heart of the debate on the impact of investment in ICT on an economy (Veeramacheneni, Ekanayake \& Vogel, 2011). The bone of contention is that, by investing in ICT, is it possible for developing countries to raise their income at the level of developed countries?

A cursory look at studies in the literature, such as Asongu and Odhiambo (2019), Bahrini and Qaffas (2019), Sezer and Abasiz (2018), and Aghaei and Mahdieh (2017) revealed that the majority of the studies mainly focused on the effect of ICT on income level. However, it would have been more informative if studies had investigated whether the impact of ICT on income varies across different African regions such as Eastern Africa, Western Africa, North Africa, Southern Africa, and Middle Africa. Additionally, examining whether real per capita income moderates the relationship between ICT and income would provide valuable insights. To the best of the researchers' knowledge, none of these studies examined the pressure real per capita income would exert on the effect of ICT on the per capita income level. This forms the motivation for this study.

Thus, the main objective of this study was to examine the effect of ICT on income levels in African countries. Specifically, the study investigated whether real per capita income influences the effect of ICT on income level and whether the effect of ICT on income level differs in the subregions of African countries. It examined, among others, the effects of the Number of Fixed Telephone Subscriptions per 100 inhabitants (FTS), Mobile Cellular subscriptions per 100 Inhabitants (MCS), the Number of Internet Users as a Percentage of the Population (IU), and the Number of Fixed Broadband Subscriptions per 100 Inhabitants (FBS) on income level in Africa.

This research was carried out across African countries, with annual data spanning 2008 to 2017 . Because data for ICT variables were unavailable before 2008 and beyond 2017 when data were being analyzed, this study considered this period. The year 2008 coincides with the emergence of ICT development in Africa.

Fifty-four African countries were considered and grouped into five sub-regions - the Eastern, Western, Northern, Southern, and Middle African. The six Eastern African countries are Tanzania, Kenya, Uganda, Rwanda, Burundi, South Sudan, Eritrea, Mauritius, Djibouti, Comoros, and Seychelles. The sixteen African countries in the Western sub-region are Nigeria, Ghana, Cote d'Ivoire, Niger, Mali, Senegal, Guinea, Benin, Liberia, Mauritania, Gambia, Guinea-Bissau, Cabe Verde, Togo, Sierra Leone, and Burkina Faso. 
The six Northern sub-regions comprise Egypt, Algeria, Sudan, Morocco, Tunisia, and Libya. The ten African countries in the Southern sub-region include Mozambique, Malawi, Zambia, Zimbabwe, South Africa, Namibia, Botswana, Lesotho, Eswatini/Swaziland, and Angola. The eleven Middle African countries are Rwanda, Burundi, Democratic Republic of Congo, Angola, Cameroon, Chad, Congo, Central African Republic, Gabon, Equatorial Guinea, Sao Tome \& Principle.

This research is organized into three sections: data and methodology (section two), results and discussion (section three), and conclusion (section four), following this introduction.

\section{Data and methodology}

Can be found the theoretical foundation of the growth of GDP per capita (i.e., economic growth) model in the neoclassical growth model, which models economic growth in terms of the Cobb-Douglas production function:

$$
\mathrm{Y}=\mathrm{AK}^{\mathrm{a}} \mathrm{N}^{1-\mathrm{a}}
$$

Where $\mathrm{A}=$ technological progress or total factor productivity, $\mathrm{K}=$ Capital stock, $\mathrm{N}=$ Labour, and $\mathrm{Y}=$ output.

Dividing equation (1) by $\mathrm{N}$ gives the per capita variables:

$$
\frac{Y}{N}=A\left(\frac{K}{N}\right)^{\alpha}\left(\frac{N}{N}\right)^{1-\alpha}
$$

Taking the logarithm of equation (2) gives

$$
\begin{aligned}
& \ln \left(\frac{Y}{N}\right)=\ln A+a \ln \left(\frac{K}{N}\right)+(1-a) \ln \left(\frac{N}{N}\right) \\
& \ln \left(\frac{Y}{N}\right)=\ln A+a \ln \left(\frac{K}{N}\right)+(1-a) \ln 1 \\
& \ln (y)=\ln A+a \ln (k)
\end{aligned}
$$

Where $\mathrm{y} \equiv \frac{\mathrm{Y}}{\mathrm{N}}$ and $\mathrm{k} \equiv \frac{\mathrm{K}}{\mathrm{N}}$

Equation (5) indicates that output per capita equals capital per capita plus the total factor productivity. This theoretical structure of the effect of a factor on output or income would help evaluate the results of the analysis of this study. 


\subsection{Model specification}

This section contains three models adapted for this study. It includes (1) Model 1 for the effects of ICT indicators and the control variables on the income level, (2) Model 2, which investigates whether per capita income influences the effect of ICT on income level; and (3) Model 3, investigating whether the effect of ICT on income level differs among sub-regions of Africa.

Inserting the relevant explanatory variables in equation 5 gives rise to the following models:

Model 1:

$\ln (y)_{i t}=\beta_{0}+\beta_{1} \operatorname{lnINV}_{i t}+\beta_{2} \operatorname{InICTI}_{i t}+\beta_{3} \operatorname{InGEXP}_{i t}+\beta_{4} \operatorname{InEXPT}_{i t}+\beta_{5} \mathrm{INF}_{\mathrm{it}}+\mu_{\mathrm{it}}$

Model 2:

$\ln (y)_{\text {it }}=\beta_{0}+\beta_{1} \operatorname{In} I N V_{i t}+\beta_{2} \operatorname{InICTI}_{\text {it }}+\beta_{3} \operatorname{InICTI}_{\text {it }} * y+\beta_{4} \operatorname{InGEXP}_{\mathrm{it}}+\beta_{5} \operatorname{InEXPT}_{\text {it }}+$ $\beta_{6} \mathrm{INF}_{i t}+\mu_{i t}$

Model 3:

$\ln (y)_{\text {it }}=\beta_{0}+\beta_{1} \operatorname{InINV}_{\text {it }}+\beta_{2} \operatorname{InICTI}_{\text {it }}+\beta_{3} \operatorname{InICTI}_{\text {it }} * \mathrm{E}+\beta_{4} \operatorname{InICTI}_{\text {it }} * \mathrm{~W}+\beta_{5} \operatorname{InICTI}_{\text {it }} *$ $\mathrm{S}+\beta_{6} \operatorname{InICTI}_{\text {it }} * \mathrm{~N}+\beta_{7} \operatorname{InGEXP}_{\text {it }}+\beta_{8} \operatorname{InEXPT}_{\text {it }}+\beta_{9} \mathrm{INF}_{\text {it }}+\mu_{i t}$

Where $\mathrm{y}=$ real per capital income proxied by GDP per capita, ICTI $=$ ICT indicators, alternatively proxied by FTS, IU, FBS, and MCS. While E, $\mathrm{W}, \mathrm{S}$, and $\mathrm{N}$ are dummy variables representing Eastern, Western, Southern and Northern sub-regions, respectively, $\beta_{0}, \beta_{1}, \beta_{2}, \beta_{3}, \beta_{4}, \beta_{5}, \beta_{6}$, and $\beta_{7}$ define parameters of the models, and subscripts $i$ and t indicate country and year, respectively, $\mu_{i t}$ is the stochastic error term, and INV = gross fixed capital formation as a percentage of GDP. In all the models, $\frac{\Delta \mathrm{k}}{\mathrm{k}}$, which represents the growth of capital stock per capita, was replaced by the share of gross fixed capital formation in the GDP, denoted by INV. This is because the data for $\frac{\Delta \mathrm{k}}{\mathrm{k}}$ is unavailable, and the only nearest suitable proxy for the growth of capital stock per capita that comes to mind is the share of gross fixed capital formation in the GDP (INV). This study realizes this to be far from being a good approximation, but this is the best that the study can do because there is no growth of capital stock statistics. It is hoped that using INV as a proxy is better than not including any proxy.

For estimation purposes, the natural $\log$ of the ICTI, GEXP, and EXPT variables, except INF, are employed in the models, thereby permitting the estimated slope parameters to be interpreted as elasticities. 
Model 1 was specified to achieve our first objective. Four ICT indicators were included one after another during estimation to give four equations estimated from Model 1. The four alternative ICT indicators were included one after another to avoid a high degree of multicollinearity. This aligns with previous studies such as Bahrini and Qaffass (2019) and Toader et al. (2018).

To achieve the second objective of this study - to examine whether per capita income influences the effect of ICT on income level-we specified Model 2, which shows real per capita income as a linear function of ICT indicators and their interactions with real income per capita. The ICT indicators were introduced into the model one after another during estimation, yielding four equation estimates.

To examine whether the effect of ICT on income level differs across the sub-regions of African countries - the third objective - each of the four alternative ICT indicators with regional dummy variables has interacted in Model 3. The dummy variables used were E, W, S, and N, each taking 1 for its corresponding African sub-region and 0 otherwise. The reference category for these four dummies is the Middle African countries. Economic growth is shown in Models 3 and 6 as a linear function of ICT indicators (ICTI) and how they interact with sub-regional dummies. The ICT indicators and their interactions with sub-regional dummies are also included one after another to avoid serious multicollinearity problems during estimation.

\subsection{Definition and measurement of variables}

The definitions of the variables employed and their measurement are described below. The data for the variables were obtained from World Bank's World Development Indicators (2019).

\subsubsection{ICT indicators}

ICT indicators (ICTI) - measured by the number of internet users, fixed telephone subscriptions, mobile-cellular subscriptions, and fixed broadband subscriptions - are assumed to impact economic growth positively. An increase in the level of each ICT indicator is posited to lead to a rise in technological progress, which in turn leads to economic growth. Technological progress would improve the production and distribution efficiency of goods and services. This postulation is in line with Farhadi, Ismail, and Fooladi (2012), Sezer and Abasiz (2018), Bahrini and Qaffas (2019), and Eboagu and Adeleye (2019). The ICT indicators are operationalized as follows: 
- The number of fixed telephone subscriptions per 100 inhabitants (FTS) refers to the sum of the active number of analogue fixed telephone lines, voice-over-IP (VoIP) subscriptions, fixed wireless local loop (WLL) subscriptions, ISDN voice-channel equivalents, and fixed public payphones (World Bank, 2019).

- Mobile cellular subscription per 100 inhabitants (MCS) According to World Bank (2019), mobile cellular telephone subscriptions are subscriptions to a public mobile telephone service that provides access to the PSTN using cellular technology. It includes the number of postpaid subscriptions and the number of active prepaid accounts that have been used during the last three months. The indicator applies to all mobile cellular subscriptions that offer voice communications. It excludes subscriptions via data cards or USB modems, subscriptions to public mobile data services, private trunked mobile radio, telepoint, radio paging, and telemetry services.

- The number of internet users as a percentage of the population (IU) represents individuals who have used the internet (from any location) in the last three months (World Bank, 2019). The internet can be used via a computer, mobile phone, personal digital assistant, games machine, digital TV, etc. It is measured as a percentage of the population.

- The number of fixed broadband subscriptions per 100 inhabitants (FBS) refers to fixed subscriptions to high-speed access to the public internet (a TCP/IP connection) at downstream speeds equal to, or greater than, $256 \mathrm{kbit} / \mathrm{s}$ (World Bank, 2019). This includes cable modem, DSL, fibre-to-the-home/building, other fixed (wired)broadband subscriptions, satellite broadband, and terrestrial fixed wireless broadband. This total is measured irrespective of the method of payment. It excludes subscriptions with access to data communications (including the internet) via mobile-cellular networks. It includes fixed WiMAX and any other fixed wireless technologies. It also consists of both residential subscriptions and subscriptions for organizations.

\subsubsection{Gross fixed capital formation (INV)}

Gross fixed capital formation, as described by World Bank (2019), includes:

- land improvements (fences, ditches, drains, and so on);

- plant, machinery, and equipment purchases; and 
- the construction of roads, railways, and the like, including schools, offices, hospitals, private residential dwellings, and commercial and industrial buildings.

According to the System of National Accounts (SNA) (1993), net acquisitions of valuables are also considered capital formation. The variable was measured as a ratio of GDP in nominal terms and local currency.

\subsubsection{Real per-capita income (y)}

This refers to gross domestic product divided by midyear population. The data used to compute per capita output growth in (3) were the same as those used here but measured at levels rather than other units.

\subsubsection{General government final consumption expenditure (GEXP)}

This variable represents all current government expenditures for purchases of goods and services, including compensation of employees (World Bank, 2019). It also includes most national defence and security expenditures but excludes government military expenditures that are part of government capital formation. The variable was measured as a ratio of GDP in nominal terms and local currency. General government final consumption expenditure was postulated to have a negative effect on productivity growth. As anecdotal evidence suggests, spending on public goods and services may be wasteful due to bribery and corruption, or the varieties of taxes imposed by the government on citizens may be greater, thereby affecting productivity adversely. Including this variable aligns with findings from studies such as Asongu and Odhiambo (2019) and Bahrini and Qaffas (2019).

\subsubsection{Export of goods and services (EXPT)}

This represents the value of all goods and other services provided to the rest of the world. According to the data source, they include the value of merchandise, freight, insurance, transport, travel, royalties, license fees, and other services, such as communication, construction, financial, information, business, personal, and government services. They exclude compensation of employees and investment income (formerly called factor services) and transfer payments. Data are measured as a ratio of GDP, with nominal terms and local currency, before expressing one as a ratio of the other. An increase in the export of goods and services (EXPT) was hypothesized to lead to increased net export through local production, low consumption of foreign goods by citizens, and low excise duties. By this, an increase in net export 
would lead to an increase in aggregate expenditure, productivity growth, and economic growth. In their respective studies, Pham and Martin (2007) and Hesse (2008) have confirmed that export has a non-linear positive effect on economic growth in their estimation.

\subsubsection{Inflation rate (INF)}

Price stability, usually measured by the inflation rate (INF), is essential for economic agents to make accurate resource allocation decisions. Some previous studies, such as (Bahrini \& Qaffas, 2019; Asongu \& Odhiambo, 2019; Eboagu \& Adeleye, 2019), have empirically confirmed that the inflation rate has a negative effect on economic growth. The inflation rate is, therefore, expected to have a negative effect on productivity growth.

\subsubsection{Regional dummies ( $\mathrm{E}, \mathrm{W}, \mathrm{S}, \mathrm{N}$, and $\mathrm{E})$}

The varying impacts of ICT on economic growth and income level among the African sub-regions are measured by the regional dummy variables $\mathrm{E}, \mathrm{W}, \mathrm{S}$, and $\mathrm{N}$, which take a value of 1 for its corresponding African sub-region, and 0 otherwise. The reference category or sub-region for the four dummies is Middle African countries. The five-way classification is adopted from the International Monetary Fund (IMF) classification of African countries.

\subsubsection{Estimation techniques}

Three-panel methods of estimations were considered in this study: pooled-OLS, fixed effect (FE), and random-effect (RE) methods. The pooled OLS estimation method, also called the common constant method, assumes no differences between the estimated cross-sections (African countries). In other words, the model estimates a common constant for all the cross-sections (African countries), and the unobservable individual effect is assumed to be zero in pooled OLS estimator (Asteriou \& Hall, 2007).

The FE estimator, known as the least-square dummy variables (LSDV) estimator, allows for estimating different constants for each group and includes a dummy variable for each group. It captures all effects specific to individuals that do not vary over time. It is possible to the fixed-effect model by including a set of time dummies. This is known as the two-way fixed effect model and has the advantage of capturing any effects that vary over time but are common across the whole panel (Asteriou \& Hall, 2007). The fixed effect is appropriate when focusing on a specific set of $\mathrm{N}$ units, say 
countries. However, it suffers from a considerable loss of degrees of freedom when many dummies are included. Including too many dummies aggravates the problem of multicollinearity among the regressors. Furthermore, it cannot be used to estimate the effect of any time-invariant variable like sex, race, religion, and other categorical variables (Baltagi, 2005). F-test is used to test the overall significance of the dummies.

The RE method is an alternative method of estimating a model. The major difference between the fixed effects and the random effects method is that the former treats the constant for each group as fixed while the latter treats the constant as random parameters (Asteriou \& Hall, 2007).

To choose among these three estimators, we carried out four decision rules tests: poolability test, Hausman test, and Breusch-Pagan Lagrange multiplier (LM) test. The poolability test determines whether a function's constant is treated as homogeneous or heterogeneous. This test also assists in knowing the appropriate estimators to use, whether pooled regression follows the OLS approach or the FE estimator. Before assessing the validity of the fixed effects method, we need to apply tests to check whether fixed effects (i.e., different constants for the various units) should indeed be included in the model. The standard F-test can check fixed effects against the simple common constant OLS method. The null hypothesis is that all the constants are the same (homogeneity), and the alternative hypothesis is that all the constants differ (heterogeneity). Suppose the p-value of the F-test is less than 0.05 level of significance (or any other chosen level of significance, say 0.01). We reject the null hypothesis (Asteriou \& Hall, 2007).

Hausman test is used to select the better model between FE and RE because both have their demerits and merits. The difference between the twopanel data models is that the FE model assumes that each country differs in its intercept term, whereas the RE model assumes that each country differs in its error term. Usually, when the panel is balanced, one might expect that the FE model will work best. In other cases, the random-effects model might be more appropriate when the sample contains limited observations of the existing cross-sectional units (Asteriou \& Hall, 2007).

Breusch-Pagan Lagrange multiplier (LM) is a test for the randomeffects model based on the OLS residual. It helps to select between a RE regression and a simple pooled OLS regression. The null hypothesis is that variance across entities is zero; there is no significant difference across units. A study rejects the null hypothesis if the p-value of the LM test is less than 0.05 significance level or any other chosen level of significance (Kalita \& India, 2013). LM test should be conducted based on the following conditions: (a) if the Poolability test indicates that simple pooled OLS regression is better 
than FE regression and (b) if the Hausman test shows that RE is better than FE regression. The Lagrange Multiplier Test is required if the above two conditions are met (Kalita \& India, 2013).

We equally carried out four post-estimation tests-multicollinearity test, autocorrelation test, heteroscedasticity test, and non-normality of the residuals test - to test the regression model's validity to determine if they violate the assumptions underlying the OLS method.

\section{Results and discussion}

This section provides the descriptive and correlation statistics, the estimates of the panel regression equations and the associated post-estimation test results. It compares the estimates of the effect of different explanatory variables on economic growth and per capita output level.

\subsection{Descriptive statistics}

Table 1 summarises the descriptive statistics for each of the variables employed in the study. It includes the mean, median, maximum, minimum, standard deviation (overall, within, and between), skewness, and kurtosis for all the variables.

Table 1 depicts the overall standard deviation for gross fixed capital formation to be about 9.26, indicating variations both over time and across units, and the standard deviation is 8.24 , indicating variations across African countries irrespective of the time period while the within the standard deviation, with the value of 4.68 , shows the variations over time. The within standard deviation is lower compared to between. That is, the data set for the variable do not change over time when compared to how it varies across African countries. The mean of gross fixed capital formation is about 23.28, with a coefficient of variation of about 0.40 . 


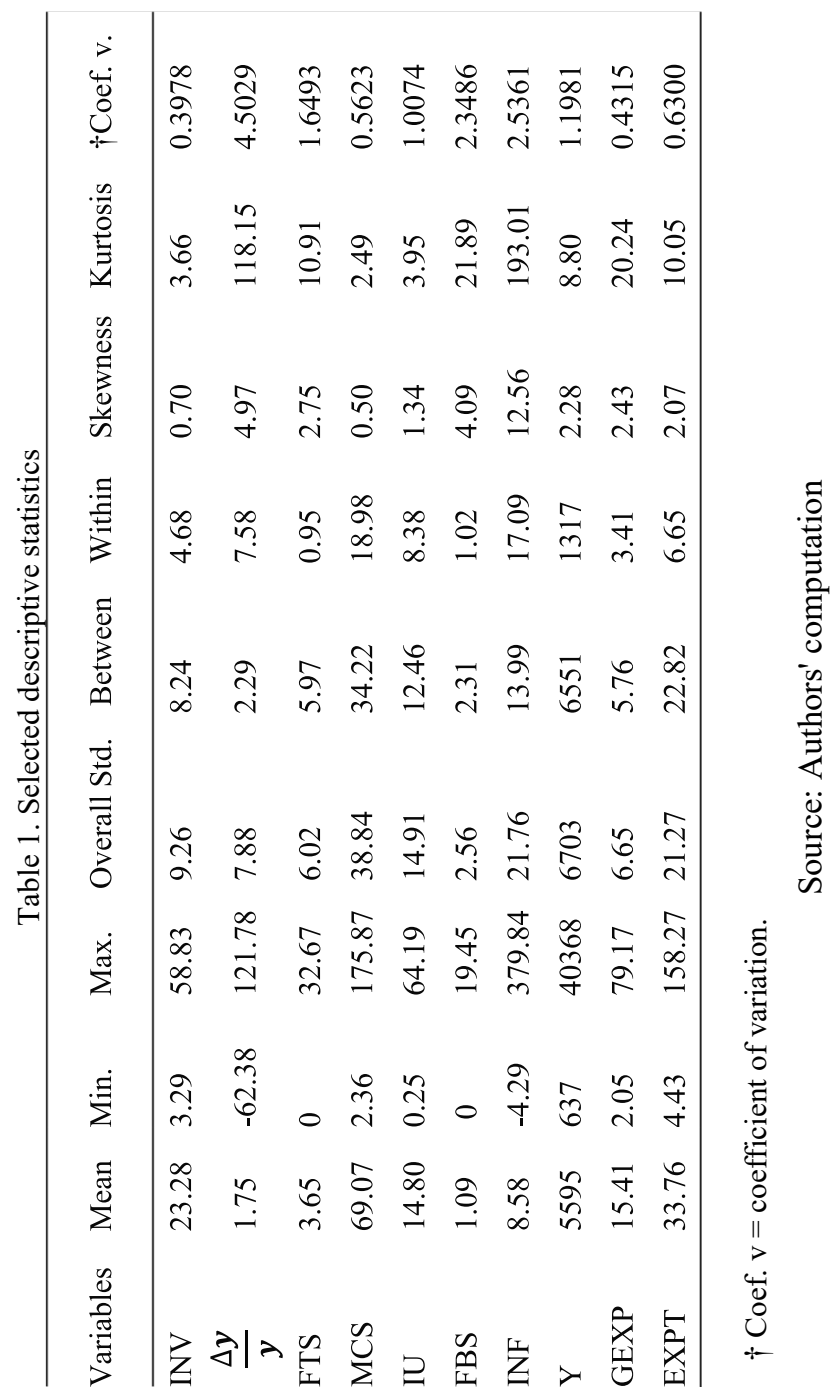

\subsection{Correlation analysis}

Table 2 shows the sample correlations between each pair of variables. The p-values of the correlation coefficients in Table 2 indicate the statistical significance of the correlation between each pair of variables. A correlation is interpreted to exist in this study if the p-value is not more than 5 per cent (i.e., $5 \%$ is the chosen cut-off significance level in the study). 


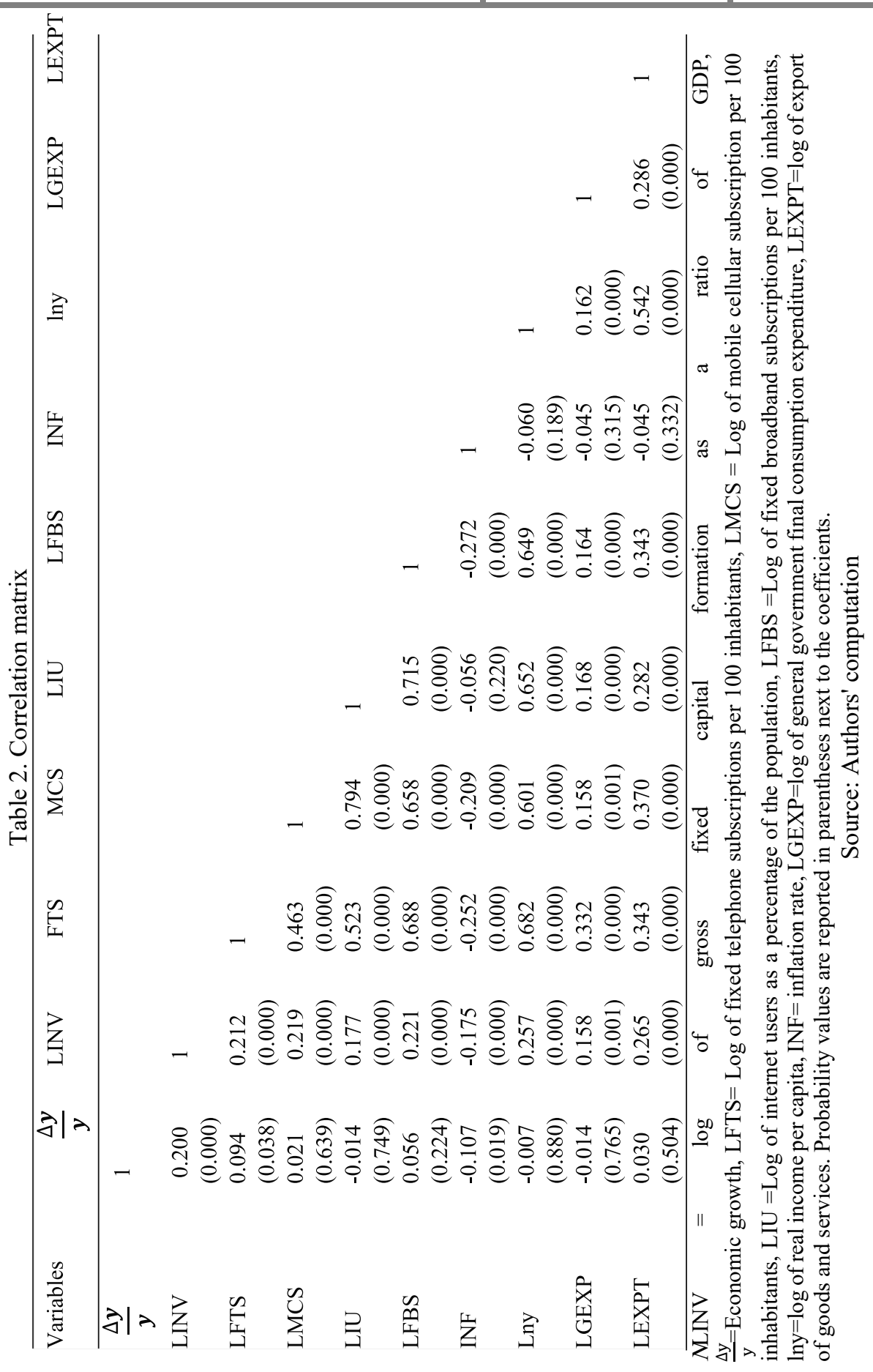




\subsection{Estimates of the effect of ICT indicators on per capita output}

The estimates for the equation of the basic per capita output level (Model 1) are given in Table 3. Equations I, II, III, and IV examine the impacts of FTS, MCS, IU, and FBS on the per capita output level, respectively.

Given the Hausman test results in Table 3, we failed to reject the null hypothesis of RE being preferred to FE in equations II, III, and IV ( $p>0.05)$. The LM test confirmed that RE was preferred to pooled OLS regression. However, the null hypothesis was rejected for equation I $(p<0.05)$. The test of poolability confirmed that the FE estimator is preferred to pooled OLS regression in equation $\mathrm{I}(\mathrm{p}<0.05)$. For these reasons, the RE method was employed for estimating equations II, III, and IV, while the FE method was considered for equation I.

The overall $\mathrm{R}^{2}$ is approximately 50 per cent in all the equations except equation 1. The p-value of the associated F-test statistics in equation $I$ is 0.061 . The Wald chi-test statistics in equations II, III, and IV are 0.000 each, indicating the overall statistical significance for all the equations. This means that all the equations, except equation I, have high goodness of fit or explanatory powers.

We carried out the Wooldridge test of autocorrelation for the four equations. We concluded that autocorrelation was present in all the equations $(p=0.0000)$. As a result of this test, we estimated a robust version of the RE regression for equations II to IV and the FE regression for equation I to correct the autocorrelation problem.

Furthermore, in respect of the test of heteroscedasticity of the residuals, we conducted a panel-modified Wald heteroscedasticity test for FE regression for only equation $\mathrm{I}$. with $\mathrm{p}=0.000$. Consequently, we rejected the null hypothesis of homoscedasticity in equation I and concluded that the errors were heteroscedastic. We thus estimated a robust FE regression to correct for the heteroscedasticity. Since equations II, III, and IV were estimated by the RE estimator, and there was no specific heteroscedasticity test for the RE estimator, we estimated robust RE regression for equations II, III, and IV to correct for the heteroscedasticity. 


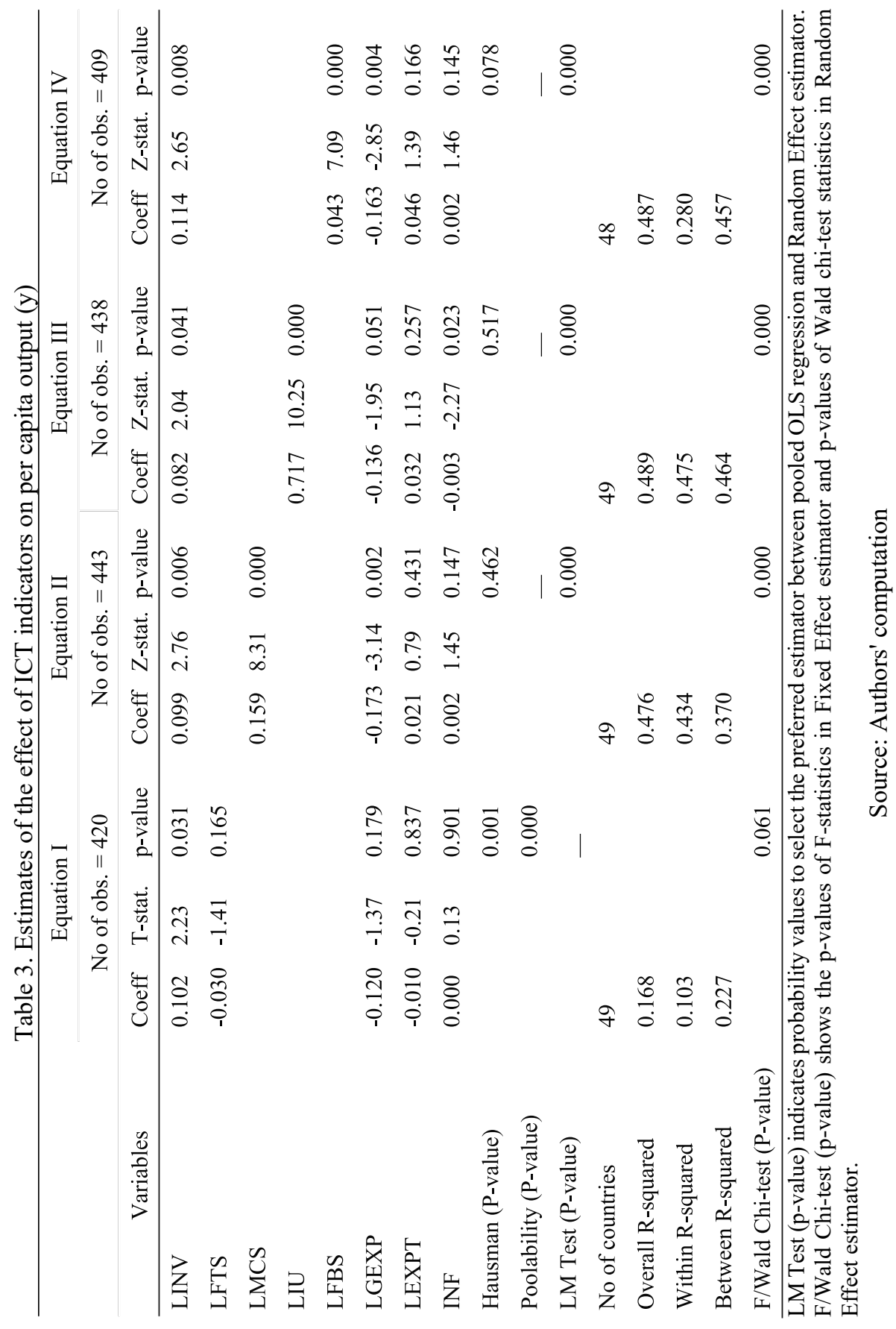


Next, we conducted a Galvao et al. (2013) test of normality, which showed that the error terms were normally distributed $(p>0.05)$ except in equation III, where $p=0.042$. Based on this, the study only rejected the null hypothesis of the normality of the residuals in equation III. It concluded that the residuals in all the equations (except equation III) were normally distributed. This situation was corrected by running a robust version of the FE regression or the RE regression to correct for the non-normality of the residuals.

Lastly, the Tolerance test of multicollinearity of the explanatory variables was carried out on the diagnostic tests. Given this, we failed to reject the hypothesis of the absence of multicollinearity in the equations as the Tolerance exceeded 0.1 in all cases and concluded that all the equations were devoid of severe multicollinearity.

Next, we examined the significance of the specific explanatory variables in the models estimated in Table 3.

The p-values of the coefficients of the LINV are 0.031, 0.006, 0.041, and 0.008 , respectively, indicating that the coefficients of LINV in all equations are positive and statistically significant (Table 3). These results support our a priori expectation and suggest that gross fixed capital formation positively affected the per capita output level. Similar evidence was found in Bahrini and Qaffas (2019) and Toader et al. (2018).

In equation I, the coefficient of LFTS is $-0.030(\mathrm{p}=0.165)$, implying that the coefficient is negative and statistically insignificant (Table 3 ). This indicates that fixed telephone subscriptions did not affect the per capita output level. However, in equation II, the coefficient of LMCS is 0.159 . The coefficient is positive and statistically significant $(\mathrm{p}=0.000)$. This implies that mobile cellular subscription positively affected per capita output level, with income elasticity of mobile cellular subscription of 0.159 .

The coefficient of LIU in equation III is positive and equals 0.717 , which means that the coefficient is statistically different from zero $(\mathrm{p}=$ 0.000 ). This implies that internet usage positively affected per capita output level, with income elasticity of internet usage of 0.717 . Similarly, the coefficient of LFBS in equation IV is positive and equals 0.043 , indicating the coefficient is statistically significant $(p=0.000)$. This suggests that fixed broadband subscription positively affected per capita output level, with income elasticity of fixed broadband subscription of 0.04 .

In sum, all the ICT indicators, except fixed telephone subscription, positively affected the per capita output level. This preponderant evidence suggests that ICT indicators positively affect the per capita output. This is consistent with the a priori expectation formed based on the findings by 
Bahrini and Qaffas (2019) and Toader et al. (2018).

The coefficients of the Log of General Government Final Consumption Expenditure (LGEXP) are $-0.120,-0.173,-0.136$, and -0.163 in equations I to IV, respectively, with respective p-values of $0.179,0.002$, 0.051 , and 0.004 . equations II and IV are negative and statistically significant, while equations I and III are also negative but statistically insignificant. This provides weak evidence that the general government's final consumption expenditure had a negative effect on the per capita income level. These results do not conform to our a priori expectations. They are, however, in accordance with the findings confirmed by Asongu and Odhiambo (2019) and Bahrini and Qaffas (2019).

Also found against our a priori expectation are the coefficients of Log of Export of Goods and Services (LEXPT), which are $-0.010(\mathrm{p}=0.837)$, $0.021(\mathrm{p}=0.431), 0.032(\mathrm{p}=0.257)$, and $0.046(\mathrm{p}=0.166)$ in equations I to $\mathrm{IV}$, respectively. Although the coefficient of LEXPT in equation I is negative and those in equations II through IV are positive, they are all statistically insignificant. This indicates that the exportation of goods and services did not affect the per capita income level. This result is consistent with Pham and Martin's (2007) and Hesse's (2008) studies. This finding probably emanates because the effect of export on the per capita income level was crowded out by excessive borrowing from private and public foreign sources, which led to a distortion of the balance of trade and devaluation of the domestic currency.

The coefficients of the inflation Rate (INF) are $0.000(\mathrm{p}=0.901)$, $0.002(p=0.147),-0.003(p=0.023)$, and $0.002(p=0.145)$ in equations I to IV, respectively. In contrast, its coefficient in equation III is negative but positive in equations I, II, and IV. Except for equation III, all the coefficients are statistically insignificant. Contrary to our a priori expectation and Toader et al. (2018) findings, this tells us that the inflation rate did not significantly affect the per capita output level. Inflation failed to affect the income level, probably because the production capacity was low while unemployment was high, leading to stagflation.

\subsection{Joint effect of ICT and real per capita income (y) on per capita output (y)}

The estimates of the four alternative equations of Model 2 are reported in Table 4. Equation 1 examines whether real per capita income influences the effect of the FTS on the per capita output level. At the same time, equations II, III, and IV replace the FTS with the MCS, IU, and FBS, respectively.

Given the Hausman test results in Table 4, we failed to reject the null 
hypothesis that $\mathrm{RE}$ is preferred to $\mathrm{FE}$ in equation $\mathrm{I}(\mathrm{p}=0.903)$. In contrast, we rejected the null hypothesis in equations II, III, and IV $(p=0.007,0.018$, and 0.042 , respectively). Furthermore, the LM test confirmed that the RE estimator is preferred to pooled OLS regression in equation I. The poolability test confirmed that FE is preferred to pooled OLS regression in equations II, III, and IV. Consequently, we employed the RE method for equation I and the FE method for equations II, III, and IV.

The overall $\mathrm{R}^{2}$ is greater than 50 per cent in the equations except equation 1 . The $\mathrm{p}$-value of the associated Wald chi-test statistics in equation I is 0.000 , and that of the F-test statistics in equations II, III, and IV are 0.000 , 0.000 , and 0.000 , respectively. This means that all four equations have high explanatory power except equation I.

We conducted the Wooldridge autocorrelation test for the four equations and concluded that the residuals were autocorrelated $(p=0.000)$ and were present in all the equations $(\mathrm{p}=0.000)$. We, therefore, estimated a robust version of the FE regressions to correct autocorrelation. We carried out a panel-modified Wald heteroscedasticity test regarding the residuals' heteroscedasticity. We rejected the null hypothesis of homoscedasticity in equations II, III, and IV ( $p=0.000$ for each equation). We concluded that the residuals of the equations were heteroscedastic. Given this result, we estimated a robust FE regression to correct for the heteroscedasticity in equations I, II, and III. Since there is no specific heteroscedasticity test for the $\mathrm{RE}$ estimator, a robust RE regression was estimated for equation I to correct the heteroscedasticity.

Next, the normality test of Galvao et al. (2013) was conducted. The test result indicated that the error terms in equations I, III, and IV were normally distributed $(\mathrm{p}>0.05)$, while that of equation II was not normally distributed $(\mathrm{p}=0.000)$. This situation was corrected by running a robust version of FE regression or RE regression to correct for the non-normality of residuals. The final validity test we carried out was a test of the multicollinearity of the explanatory variables. Using the Tolerance test, we failed to reject the hypothesis of the absence of multicollinearity in the equations (Tolerance $>0.1$ in all cases). This implies that all equations are devoid of severe multicollinearity.

Having just evaluated the overall diagnostic statistics of each of the equations, we advanced to examine the performance of the specific explanatory variables in the equations as follows. 


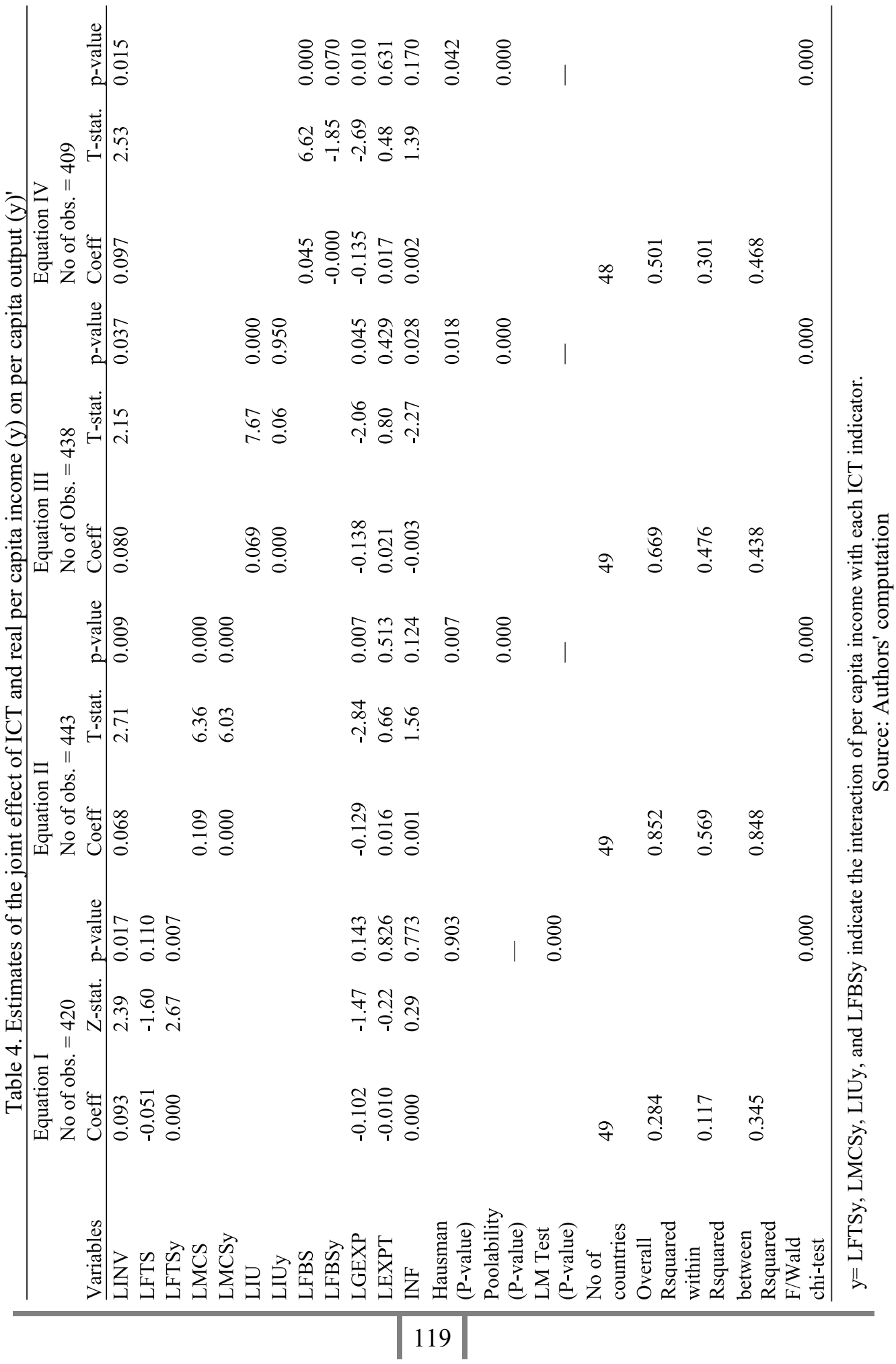


From Table 4, the coefficients of the Log of Gross Fixed Capital Formation (LINV) are $0.093(p=0.017), 0.068(p=0.009), 0.080(p=0.037)$, and $0.097(\mathrm{p}=0.015)$ in equations I through IV, respectively. This indicates that the coefficients of LINV in all the equations are positive and statistically significant. In line with our a priori expectation, gross fixed capital formation positively affected the per capita output level. Similar findings were reported by (Bahrini \& Qaffas, 2019; Hodrab et al., 2016; Shanmugam \& Kuppusamy, 2007).

In equation I (Table 4), the coefficients of the Log of Fixed Telephone Subscriptions (LFTS) and its interaction with per capita income (LFTSy) are respectively $-0.051(p=0.110)$ and $-0.000(p=0.007)$, which shows that both coefficients are negative and only LFTSy is statistically significant. This implies that the fixed telephone subscription, in its own right, did not affect the per capita output level, but per capita income made it affect the per capita output level.

In equation II of Table 4, the coefficients of the Log of Mobile Cellular Subscriptions (LMCS) and its interaction with per capita income (LMCSy) are $0.109(\mathrm{p}=0.000)$ and $0.000(\mathrm{p}=0.000)$, respectively. This indicates that both coefficients are positive and statistically significant. This suggests that mobile cellular subscription positively affected per capita output level and was more effective in promoting per capita output level in higherincome group countries than in their lower-income counterparts.

The coefficients of the Log of Internet Users as a percentage of total population (LIU) and its interaction with per capita income (LIUy) are 0.069 $(p=0.000)$ and $0.000(p=0.950)$, respectively (Table 4 , equation III). This points out that both the coefficients of LIU and LIUy are positive. However, only the former is statistically significant, suggesting that internet usage positively affected the per capita output level and did not affect the per capita output level in higher-income countries.

The coefficients of the Log of Fixed Broadband Subscriptions (LFBS) and its interaction with per capita income (LFBSy) in equation IV of Table 4, respectively, are $0.045(\mathrm{p}=0.000)$ and $-0.000(\mathrm{p}=0.070)$. This depicts that the coefficients of LFBS and LFBSy are positive and negative, respectively, but only LFBS is statistically significant. This points out that internet usage positively affects the per capita output level, and per capita income does not influence the effect of internet usage on the per capita output level.

Of all ICT indicators, only mobile cellular and fixed telephone subscriptions affect the per capita output level in countries with higherincome groups. Thus, the overall picture emerging from the findings is that there is weak evidence to conclude that ICT indicators affect per capita output 
levels in higher-income countries.

The coefficients of the Log of General Government Final Consumption Expenditure (LGEXP) were estimated to be $-0.102(\mathrm{p}=0.143)$, $-1.129(\mathrm{p}=0.007),-0.138(\mathrm{p}=0.045)$, and $-0.135(\mathrm{p}=0.010)$ in equations $\mathrm{I}$, II, III, and IV, respectively (Table 4). This indicates that the coefficients of LGEXP in all the equations are negative and statistically significant except in equation I. In accordance with our a priori expectation and the findings reported by (Asongu \& Odhiambo, 2019; Bahrini \& Qaffas, 2019), this portrays that general government final consumption expenditure had a robust negative effect on per capita output level.

In Table 4, the coefficients of the Log of Export of Goods and Services (LEXPT) were estimated to be $-0.010(p=0.826), 0.016(p=0.513), 0.021$ $(p=0.429)$, and $0.017(p=0.631)$ in equations I through IV, respectively. This indicates that the coefficients of LEXPT in all equations are positive (except in equation I) and statistically insignificant, indicating that the exportation of goods and services did not affect the per capita output level. This result follows our a priori expectation and the literature, especially the findings reported by (Pham \& Martin, 2007; Hesse, 2008). This could be because the effect of export on per capita income level had been crowded out by excessive borrowing from private and public foreign sources, which led to a distortion of the balance of trade and devaluation of the domestic currency.

The coefficients of Inflation rate (INF) are $0.000(p=0.773), 0.001(p$ $=0.124),-0.003(\mathrm{p}=0.028)$, and $0.002(\mathrm{p}=0.170)$ in equations I to IV, respectively, indicate that only the coefficient of equation III is statistically significant. In contrast, other coefficients are not statistically significant. Against our a priori expectation and findings by Asongu and Odhiambo (2019) and Eboagu and Adeleye (2019), this suggests that the inflation rate did not have a robust negative effect on the per capita output level. As the inflation rate rose, it failed to affect income because of the low production capacity, and unemployment increased.

\subsection{Estimates of the joint effect of ICT and region on per capita output (y)}

The estimates of the four versions of Model 6 are reported in Table 5. equations I, II, III, and IV are concerned with the effects of the FTS, MCS, IU, and FBS on per capita output levels across the sub-regions of African countries. 
Table 5. Estimates of the joint effect of ICT and region on per capita output (y)

\begin{tabular}{|c|c|c|c|c|c|c|c|c|c|c|c|c|}
\hline \multirow[b]{2}{*}{ Variables } & \multicolumn{3}{|c|}{$\begin{array}{l}\text { Equation I } \\
\text { No of obs. }=420\end{array}$} & \multicolumn{3}{|c|}{$\begin{array}{l}\text { Equation II } \\
\text { No of obs. }=443\end{array}$} & \multicolumn{3}{|c|}{$\begin{array}{l}\text { Equation III } \\
\text { No of obs. }=438\end{array}$} & \multicolumn{3}{|c|}{$\begin{array}{l}\text { Equation IV } \\
\text { No of obs. }=409\end{array}$} \\
\hline & Coeff & $\begin{array}{l}\text { T- } \\
\text { stat. }\end{array}$ & $\begin{array}{l}\text { p- } \\
\text { value }\end{array}$ & Coeff & $\begin{array}{l}\text { T- } \\
\text { stat. }\end{array}$ & $\begin{array}{l}\text { p- } \\
\text { value }\end{array}$ & Coeff & $\begin{array}{l}\text { T- } \\
\text { stat }\end{array}$ & $\begin{array}{l}\mathrm{p}- \\
\text { value }\end{array}$ & Coeff & $\begin{array}{l}\text { Z- } \\
\text { stat. }\end{array}$ & $\begin{array}{l}\text { p- } \\
\text { value }\end{array}$ \\
\hline LINV & 0.098 & 2.09 & 0.042 & 0.104 & 2.84 & 0.007 & 0.093 & 2.61 & 0.012 & 0.122 & 3.09 & 0.002 \\
\hline LFTS & 0.007 & 0.18 & 0.860 & & & & & & & & & \\
\hline LFTSE & -0.025 & -0.44 & 0.662 & & & & & & & & & \\
\hline LFTSW & -0.050 & -1.07 & 0.289 & & & & & & & & & \\
\hline LFTSS & -0.068 & -1.44 & 0.157 & & & & & & & & & \\
\hline LFTSN & -0.123 & -1.79 & 0.080 & & & & & & & & & \\
\hline LMCS & & & & 0.091 & 1.91 & 0.062 & & & & & & \\
\hline LMCSE & & & & 0.068 & 0.96 & 0.344 & & & & & & \\
\hline LMCSW & & & & 0.055 & 1.01 & 0.316 & & & & & & \\
\hline LMCSS & & & & 0.143 & 2.47 & 0.017 & & & & & & \\
\hline LMCSN & & & & 0.127 & 1.64 & 0.107 & & & & & & \\
\hline LIU & & & & & & & 0.014 & 0.50 & 0.620 & & & \\
\hline LIUE & & & & & & & 0.092 & 2.48 & 0.017 & & & \\
\hline LIUW & & & & & & & 0.050 & 1.78 & 0.081 & & & \\
\hline LIUS & & & & & & & 0.084 & 2.58 & 0.013 & & & \\
\hline LIUN & & & & & & & 0.128 & 2.24 & 0.029 & & & \\
\hline LFBS & & & & & & & & & & 0.012 & 1.02 & 0.309 \\
\hline LFBSE & & & & & & & & & & 0.040 & 2.51 & 0.012 \\
\hline LFBSW & & & & & & & & & & 0.021 & 1.33 & 0.184 \\
\hline LFBSS & & & & & & & & & & 0.055 & 3.01 & 0.003 \\
\hline LFBSN & & & & & & & & & & 0.115 & 4.06 & 0.000 \\
\hline LGEXP & -0.103 & -1.31 & 0.197 & -0.165 & -3.23 & 0.002 & -0.122 & -2.33 & 0.024 & -0.162 & -3.25 & 0.001 \\
\hline LEXPT & -0.002 & -0.04 & 0.965 & 0.018 & 0.63 & 0.532 & 0.024 & 0.93 & 0.355 & 0.060 & 1.79 & 0.073 \\
\hline INF & 0.000 & 0.10 & 0.922 & 0.002 & 1.39 & 0.172 & -0.002 & -2.28 & 0.027 & 0.002 & 1.78 & 0.076 \\
\hline Hausman & & & 0.000 & & & 0.000 & & & 0.000 & & & 0.324 \\
\hline Poolability & & & 0.000 & & & 0.000 & & & 0.000 & & & - \\
\hline $\begin{array}{l}\text { LM Test } \\
\text { (P-value) }\end{array}$ & & & - & & & - & & & - & & & 0.000 \\
\hline $\begin{array}{l}\text { No of } \\
\text { countries }\end{array}$ & 49 & & & 49 & & & 49 & & & 48 & & \\
\hline $\begin{array}{l}\text { Overall } \\
\text { R-squared }\end{array}$ & 0.504 & & & 0.583 & & & 0.501 & & & 0.572 & & \\
\hline $\begin{array}{l}\text { within } \\
\text { R-squared }\end{array}$ & 0.119 & & & 0.453 & & & 0.549 & & & 0.335 & & \\
\hline $\begin{array}{l}\text { between } \\
\text { R-squared }\end{array}$ & 0.278 & & & 0.340 & & & 0.357 & & & 0.365 & & \\
\hline $\begin{array}{l}\text { F/Wald chi-test } \\
\text { (P-value) }\end{array}$ & & & 0.014 & & & 0.000 & & & 0.000 & & & 0.000 \\
\hline
\end{tabular}

E, W, S, N, and M indicate the dummy variables for the Sub-regional African countries. LFTS, LFTSE, LFTSW, LFTSS, LFTSN, LMCS, LMCSE, LMCSW, LMCSS, LMCSN, LIU, LIUE, LIUW, LIUS, LIUN, LFBS, LFBSE, LFBSW, LFBSS, and LFBSN indicate both the reference categories and the ICT indicators interacted with the Sub-regional dummy variables.

Source: Authors' computation 
The Hausman test results in the table indicate that we failed to reject the null hypothesis that RE prefers the FE estimator in equation IV ( $\mathrm{p}=$ $0.324)$. However, we reject the hypothesis in equations I ( $p=0.000)$, II $(p=$ $0.000)$, and III $(\mathrm{p}=0.000)$. The poolability test confirmed that the FE estimator was preferred to pooled OLS regression in equations I, II, and III (p $<0.05$ ). Given these results, we employed the FE method for equations I, II, and III and the RE method for equation IV.

In Table 5, the overall $\mathrm{R}^{2}$ is approximately 50 per cent in each equation. The $\mathrm{p}$-value of the associated Wald chi-test statistics in equation IV is 0.000 and, that of the F-test statistics in equations I, II, III are 0.014, 0.000, and 0.000 , respectively, indicating that all four equations have high goodness of fit or explanatory power.

An autocorrelation test of the residuals (Wooldridge test) was carried out for equations 1 through IV. The Wooldridge test $(p=0.000)$ suggested autocorrelation was present in all the equations. We, therefore, estimated a robust version of the FE regression to correct for the autocorrelation.

A heteroscedasticity test of the residuals was also carried out using a panel-modified Wald heteroscedasticity test for FE regression, which shows a p-value of 0.000 for only equations I, II, and III. Given these results, we rejected the null hypothesis of homoscedasticity for equations I, II, and III. We concluded that the residuals were heteroscedastic in these three equations. Consequently, we estimated a robust FE regression to correct the heteroscedasticity in equations I through III, while a robust RE regression was also estimated for equation IV.

Galvao et al. (2013) test of normality conducted shows that the error terms were normally distributed $\{\mathrm{p}$ (chi-square) $>0.05\}$. However, a robust version of Fixed Effect (FE) regression was employed for the estimation.

Using the Tolerance test, we also tested the multicollinearity of the explanatory variables. Since the Tolerance exceeds 0.1 for all equations, we did not reject the null hypothesis of the absence of multicollinearity. We concluded that all equations were devoid of severe multicollinearity.

Having evaluated the overall diagnostic statistics of each equation, we examined the performance of the specific explanatory variables.

In Table 5, the coefficients of the Log of Gross Fixed Capital Formation (LINV) are $0.098(\mathrm{p}=0.042), 0.104(\mathrm{p}=0.007), 0.093(\mathrm{p}=0.012)$, and $0.122(\mathrm{p}=0.002)$ in equations I, II, III, and IV respectively, indicating that the coefficients of LINV in all the equations are positive and statistically significant. In accordance with our a priori expectation and findings reported by (Bahrini and Qaffas, 2019; Hodrab et al., 2016; Shanmugam \& Kuppusamy, 2007), these results suggest that gross fixed capital formation 
had a positive effect on per capita output level.

The coefficients of the log of General Government Final Consumption Expenditure (LGEXP) are $-0.103(\mathrm{p}=0.197),-0.165(\mathrm{p}=0.002),-0.122(\mathrm{p}=$ $0.024)$, and $-0.162(\mathrm{p}=0.001)$ in equations I, II, III, and IV, respectively, depicting that the coefficients are negative in all equations. However, while its coefficients in all equations II, III, and IV are statistically significant, its coefficient in equation I is statistically insignificant. This indicates that the general government's final consumption expenditure had a robust negative effect on the per capita output level. These results agree with our a priori expectation and the findings reported by (Asongu \& Odhiambo, 2019; Bahrini \& Qaffas, 2019). These results are probably obtained because the government's recurrent expenditures are small relative to capital expenditures. The recurrent effect expenditure was supposed to have on GDP might have been crowded out by imposing high commodity and income taxes.

The coefficients of the log of Export of Goods and Services (LEXPT) are $-0.002(\mathrm{p}=0.965), 0.018(\mathrm{p}=0.532), 0.024(\mathrm{p}=0.355)$, and $0.060(\mathrm{p}=$ 0.073 ) in equations I, II, III, and IV respectively, depicting that all the coefficients are positive (except for equation I) though statistically insignificant. This indicates that the exportation of goods and services did not affect the per capita output level. This finding does not conform to our a priori expectation and finding from previous studies such as Pham and Martin (2007) and Hesse (2008). It could be that the effect of export on per capita income level had been crowded out by excessive borrowing from private and public foreign sources, which led to a distortion of the balance of trade and devaluation of the domestic currency.

The coefficients of inflation rate (INF) are $0.000(\mathrm{p}=0.922), 0.002(\mathrm{p}$ $=0.172),-0.002(p=0.027)$, and $0.002(p=0.076)$ in equations I, II, III, and IV, respectively, depicting that the coefficients of INF in equation III are negative but positive in equation I, II, and IV. Equations I, II, and IV coefficients are not statistically significant but significant in equation III. These results do not provide strong evidence that the inflation rate had a negative effect on the per capita output level, which was our a priori expectation. However, similar findings were reported by (Asongu \& Odhiambo, 2019; Eboagu \& Adeleye, 2019).

As regards the effect of ICT indicators on per capita output level, equation I indicates that the effect (negative) of the fixed telephone subscription on per capita output level did not differ among the sub-region of African countries. This is because the probability values of the reference category and the FTS interacted with sub-regional dummy variables are all greater than 0.05 significant levels. While equation II shows that the effect of 
mobile cellular subscriptions on per capita output level is higher for only Southern African countries when compared with reference group countries and other sub-regional countries. Equation III indicates that the effect of internet usage on per capita output levels is higher in Eastern, Southern, and Northern African countries compared to reference group countries (Middle African countries) and other sub-regional countries. Equation IV similarly indicates that the effect of the fixed broadband subscription on per capita output level is higher for Eastern, Southern, and Northern African countries compared to reference group countries (Middle African countries) and other sub-regional countries.

\section{Conclusion}

Based on the objectives and findings above, three main conclusions are drawn from this study: (1) ICT positively affects income level in Africa; (2) real income per capita influences the effect of ICT on income level (3) the effect of ICT on income level differs among African regions, and that the effect is larger in Eastern, Southern and Northern African countries than other regions.

Given this empirical evidence, policies should be targeted toward improving the ICT indicators development in each African country to uplift countries within the low-income group category to that of the higher-income group. Authorities in Western and Middle African countries should beef up investment in ICT to optimally exploit the benefits of ICT.

As for the control variables, general government final consumption expenditure has a negative effect on income level, while gross fixed capital formation positively affects income level. Inflation and the export of goods and services do not influence the per capita output level. Hence, authorities need to implement policies increasing gross fixed capital formation. We recommend that policymakers not rely on general government final consumption expenditure as a factor that raises per capita output. 


\section{Declaration of conflicting interests}

The author(s) declared no potential conflicts of interest with respect to the research, authorship, and/or publication of this article.

\section{References}

Aghaei, M., \& Mahdieh, R. (2017). The impact of information and communication technology (ICT) on economic growth in the OIC countries. Environmental and Socio-Economic Studies 17(2), 255-76. https://doi.org/10.25167/ees.2017.42.7

Asongu, S., \& Odhiambo, N. (2019). Foreign direct investment, information technology and economic growth dynamics in sub-Saharan Africa. EXCAS Working Paper WP/19/038. SSRN. https://doi.org/10.2139/ssrn.3417047

Asteriou, D., \& Hall, S.G. (2006). Applied econometrics, A modern approach (Rev. ed.). Palgrave Macmillan.

Bahrini, R., \& Qaffas A. A. (2019). Impact of information and communication technology on economic growth: evidence from developing countries. Economies, 7(1), 21. https://doi.org/10.3390/economies7010021

Baltagi, B. H. (2005). Econometric analysis of panel data (3rd ed.). John Wiley \& Sons Ltd.

Can, H., \& Terziev, V. (2016). The relationship economic growth and information technologies. SSRN. http://dx.doi.org/10.2139/ssrn.3383899

Eboagu, C., \& Adeleye, N. (2019). Evaluation of ICT development and economic growth in Africa. Netnomics, 20, 31-53. https://doi.org/10.1007/s11066-019-09131-6

Farhadi, M., Ismail, R., \& Fooladi, M. (2012). Information and communication technology use and economic growth. PLoS ONE 7(11), e48903. https://doi.org/10.1371/journal.pone.0048903

Galvao, A. F., Montes-Rojas, G., Sosa-Escudero, \& Wang, L. (2013). Test for skewness and kurtosis in the one-way error component model. Journal of Multivariate Analysis, 122, 35-52. https://doi.org/10.1016/j.jmva.2013.07.002

Hesse, H. (2008). Export Diversification and economic growth. Commission on Growth and Development Working Paper; No. 21. World Bank, Washington. https://openknowledge.worldbank.org/handle/10986/28040

Hodrab, R., Maitah M., \& Lubos S. (2016). The effect of information and communication technology on economic growth: Arab world case. Journal of Economics and Financial Issues, 6(2), 765-775.

Kalita, G. \& India, R. T. (2013). Panel regression in Stata: An introduction to type of models and tests. STATA Users Group Meeting 1st August 2013, Mumbai. https://www.stata.com/meeting/india13/materials/in13_kalita.pdf

Pham, C., \& Martin W. (2007). Extensive and intensive margin growth and developing country exports. World Bank, Washington D.C.

Sezer, S., \& Abasiz, T., (2018). The effect of information and communication technologies on economic growth in OECD Countries. Annals of the Constantin Brâncuşi University of Târgu Jiu, Economy Series, 6, 31-36.

Shanmugam, B., \& Kuppusamy, M. (2007). Islamic countries economic growth and ICT development: The Malaysian case. Journal of Economic Cooperation, 28(1), 99114.

Toader, E., Firtescu, B., Roman, A., \& Anton, S. (2018). Impact of Information and Communication Technology Infrastructure on Economic Growth: An Empirical 
Assessment for the EU Countries. Sustainability, 10(10), 3750. https://doi.org/10.3390/su10103750

Veeramacheneni, B., Ekanayake, E. M., \& Vogel, R. (2011). Information technology and economic growth: A causal analysis. Southwestern Economic Review, 34, 75-88.

World Bank. (2019). World development indicators. World Bank, Washington, DC. https://datatopics.worldbank.org/world-development-indicators 